\title{
Variables Associated With Return to Sport Following Anterior Cruciate Ligament Reconstruction: A Systematic Review
}

\author{
Sylvia Czuppon, PT, DPT, OCS [Assistant Professor of Physical Therapy and Orthopedic \\ Surgery] \\ Program in Physical Therapy, Washington University School of Medicine, 4444 Forest Park Ave., \\ Campus Box 8502, St. Louis, Missouri 63108, United States
}

Brad A. Racette, MD [Professor of Neurology]

Department of Neurology, Washington University School of Medicine, 660 South Euclid Avenue, Campus Box 8111, St. Louis, Missouri, 63110. United States

Sandra E. Klein, MD [Assistant Professor of Orthopedic Surgery]

Department of Orthopedic Surgery, Washington University School of Medicine, 660 South Euclid Avenue, Campus Box 8111, St. Louis, Missouri, 63110. United States

\section{Marcie Harris-Hayes, PT, DPT, MSCI, OCS [Assistant Professor of Physical Therapy and Orthopedic Surgery] \\ Program in Physical Therapy, Washington University School of Medicine, 4444 Forest Park Ave., Campus Box 8502, St. Louis, Missouri, 63108. United States}

\begin{abstract}
Background-As one of the purposes of anterior cruciate ligament reconstruction (ACLR) is to return athletes to their pre-injury activity level, it is critical to understand variables influencing return to sport. Associations between return to sport and variables representing knee impairment, function and psychological status have not been well studied in athletes following ACLR.
\end{abstract}

Purpose-The purpose of this review is to summarize the literature reporting on variables proposed to be associated with return to sport following anterior cruciate ligament reconstruction.

Study Design-Systematic Review

Methods-Medline, Embase, CINAHL and Cochrane databases were searched for articles published before November 2012. Articles included in this review met these criteria: 1) included patients with primary ACLR, 2) reported at least one knee impairment, function or psychological measure, 3) reported a return to sport measure and 4) analyzed the relationship between the measure and return to sport.

Results-Weak evidence existed in sixteen articles suggesting variables associated with return to sport included higher quadriceps strength, less effusion, less pain, greater tibial rotation, higher Marx Activity score, higher athletic confidence, higher pre-operative knee self-efficacy, lower kinesiophobia and higher pre-operative self-motivation.

Corresponding Author: Sylvia Czuppon, PT, DPT, OCS: Phone: 314-286-1578, Fax: 314-286-1473, czuppons@wustl.edu.. Contributorship Statement: The four authors are justifiably credited with authorship, according to the authorship criteria. In detail: SC - conception, performed part of the literature search, determination of final articles, analysis and interpretation of data, drafting of the manuscript, final approval given; BR - critical revision of manuscript, final approval given; SK - critical revision of manuscript, final approval given; $\mathrm{MHH}$ - determination of final articles, analysis and interpretation of data, critical revision of the manuscript, final approval given. SC is the guarantor. 
Conclusion-Weak evidence supports an association between knee impairment, functional, and psychological variables and return to sport. Current return to sport guidelines should be updated to reflect all variables associated with return to sport. Utilizing evidence-based return to sport guidelines following ACLR may ensure athletes are physically and psychologically capable of sports participation, which may reduce re-injury rates and the need for subsequent surgery.

\section{Keywords}

anterior cruciate ligament reconstruction; return to sport; psychological; rehabilitation

\section{BACKGROUND}

Anterior cruciate ligament (ACL) tears are the most commonly reported knee injury in athletes, with nearly 300,000 anterior cruciate ligament reconstructions (ACLR) performed yearly in the United States.[1] Previous reports indicate that $98 \%$ of orthopaedic surgeons recommend surgery if patients wish to return to sport,[2] but not all patients return to sport following ACLR. Clinical guidelines suggest that patients should be expected to return to sport by nine months post-surgery, but many patients have not achieved this activity level up to 18 months after receiving clearance to return to sport.[3] Declines in sports participation compared to pre-injury levels are noted as far as five and seven years post-surgery,[4-7] though reasons for activity level changes may be unrelated to knee function.

Improved understanding of variables influencing patients' ability to return to sports is needed. Return to sport recommendations following ACLR are varied and often based on clinical experience or reviews reporting the criteria utilized in randomized control trials (RCTs).[8-11] Most return to sport criteria following ACLR includes assessments of knee impairment and function, such as knee range of motion (ROM), quadriceps strength and functional test performance. Achieving knee ROM equivalent to the uninvolved limb is frequently emphasized[12-17] as ROM asymmetry between limbs has been linked to worse subjective outcomes 10 years post-surgery, though the ability of these patients to return to sport is unknown.[18] Quadriceps and hamstring strength are the most commonly utilized objective criteria when determining patient readiness to return to sport,[13, 14, 16, 19-26] and published reports note persistent quadriceps weakness years after surgery.[27, 28] Typical criteria include a quadriceps limb symmetry index (LSI) equivalent to $>80-90 \%$ of the opposite side.[13, 14, 16, 19-26] Although quadriceps weakness may alter knee kinematics during running and cutting,[29] the actual relationships between quadriceps strength and functional test performance such as hop testing is unclear.[30-34] Single leg hop LSI $\geq 90 \%$ is also often cited,[15, 23, 25, 35-38] but the relationship between functional test performance and athletic performance is not well established.[39] Despite post-surgical emphasis on strengthening and functional performance, abnormal lower limb kinematics are evident during hopping and jumping two to four years following ACLR.[40, 41] The ability of these frequently utilized clinical criteria to predict athletes' ability to return to sport is unknown.

Some patients without impairments in ROM or strength may choose not to return to their pre-injury level of sports participation for reasons unrelated to knee function, such as lifestyle changes. Conversely, some patients reporting substantial knee impairments after ACLR return to competitive sport.[42] Psychological variables may partially explain the lack of association between physical function and return to sport.[43-45] Fear of movement and re-injury, or kinesiophobia, is one of the most commonly cited reasons patients do not return to sport following ACLR.[46] Although kinesiophobia declines during rehabilitation, [47] it is still reported in as high as $20-24 \%$ of patients.[6, 48] Higher perceived selfefficacy (one's judgment about whether one can perform a task) $[49,50]$ and an internal 
health locus of control[51, 52] have been linked to better quality of life scores, knee function and subjective outcomes post-ACLR. Despite these reports, psychological measures are not typically used in current return to sport criteria following ACLR.

The evidence supporting current clinical criteria used to allow patients to return to sport following ACLR has not been thoroughly examined. The primary purpose of this systematic review is to summarize the published literature reporting on knee impairment, functional, and psychological variables proposed to be associated with return to sport following ACLR. Knowledge of variables associated with athletes' return to play following surgery may aid clinicians in counseling patients and focusing rehabilitation programs. The secondary purpose of this review is to provide recommendations for future research to develop evidence-based return to sport criteria.

\section{METHODS}

\section{Search Strategy}

Medline, CINAHL, Embase and the Cochrane Database were searched for articles published in print or electronically prior to November 2012. Subject mapping and key words were used for each search engine, including anterior cruciate ligament surgery and/or injury, preoperative care, post-operative care, range of motion, muscle strength, proprioception, kinesiophobia, psychological, recovery of function and return to sports/return to play/sports re-entry. A reference librarian assisted with the database searches. A sample search is shown in Appendix 1. Two board-certified orthopaedic physical therapists independently applied the inclusion/exclusion criteria to these articles. The Preferred Reporting Items for Systematic reviews and Meta-Analyses (PRISMA) flow diagram of the search results is shown in Figure 1.[53]

\section{Selection Criteria}

Inclusion criteria for the articles selected were: (1) patients had undergone primary ACLR, (2) English language, (3) at least one knee impairment, functional, or psychological measure was reported, (4) return to sport (defined as any sport, the same sport, and the same level of pre-injury sport at any post-surgical timeframe) was reported via subjective report or any measure directly identifying the patients' level of active sports participation, such as the Tegner Activity score or study-defined criteria, and (5) studies contained statistical analyses examining the association between variables of interest and return to sport. Exclusion criteria were concomitant surgery of other ligaments or microfracture surgery. Concomitant meniscectomy or meniscal repair, or history of contralateral ACLR was permitted. Studies simply identifying whether patients could perform sport-related tasks but not reporting actual return to sport were excluded. Thus, measures such as the International Knee Documentation Committee (IKDC) objective form score, Cincinnati Knee Rating Scale score and the Lysholm Knee score did not meet the definition of a return to sport measure for this review. Two reviewers independently reviewed titles and abstracts, then full text of potentially relevant articles, and attained consensus on articles to be included in the review.

\section{Data Extraction and Analysis}

Once articles meeting the inclusion criteria were identified, the lead author independently extracted information from each article. Information identified for descriptive analysis included study population, follow-up timeframe, pre-injury athletic participation, return to sport rate, knee impairment and functional outcomes, psychological outcomes, and statistical analyses relating variables of interest to return to sport. If data such as return to sport rate was not directly reported within a study, it was calculated with available data. A second reviewer confirmed all information. As a framework for data analysis, strength of evidence 
was classified according to Logerstedt et al.[54] Evidence is considered strong when supported by numerous high-quality RCTs, moderate when supported by either a single high quality RCT or numerous low-quality RCTs or cohort studies, and weak when supported by retrospective or case controlled studies.

\section{Assessment for Risk of Bias}

Using the 11 item checklist recommended by the Cochrane Collaboration Back Review Group,[55] two reviewers independently assessed each study for methodological risk of bias and discrepancies were resolved by consensus (Appendix 2). These criteria assess study characteristics related to selection bias, performance bias, attrition bias and detection bias. Van Tulder et al.[56] reported that RCTs meeting fewer than 6 criteria reported approximately $50 \%$ greater effect sizes than those meeting $\Varangle 6$ criteria, indicating that studies with lower methodologic quality may have exaggerated results. Therefore, in this review, articles were classified as having a "high risk" ( $<6$ "yes" responses) or "low risk" of bias ( $\$ "yes" responses).

Two reviewers independently rated the level of evidence of the final selected articles according to the Oxford Centre for Evidence Based Medicine.[57] This system is a systematic approach to rank strength of evidence according to the type of clinical question involved. Levels of evidence range from 1 to 5 where Level 1 studies are regarded to contain the highest quality of evidence. Consensus was obtained between both reviewers for each article's risk of bias and level of evidence rating.

\section{RESULTS}

Initial database searches identified 1372 potential articles with 183 articles selected for detailed review (Figure 1). 16 articles were included in the final review (Table 1).

\section{Study design}

Of the 16 articles, $[6,48,49,58-70]$ four were RCTs.[62, 63, 67, 70] The remaining 12 studies were prospective cohort design [49, 58-60, 64, 68] or cross-sectional studies.[6, 48, $61,65,66,69]$ Four included multivariate analyses to control for variables (such as age, gender, education, height, weight, body mass index, time since surgery) that may have affected their results.[49, 64-66] Six studies were rated as Level 2[49, 58, 63-67, 69] and ten were rated Level 4.[6, 48, 58-62, 68, 70] All studies[6, 48, 49, 58-70] were rated as having a high risk of bias (Appendix 2).

\section{Patient Characteristics}

All 16 studies $[6,48,49,58-70]$ included both men and women. Women comprised between $3-45 \%$ of patients within studies. Mean age ranged from 22-30 years. Patellar tendon graft was used exclusively for reconstruction in four studies, $[59,60,65,70]$ hamstring graft exclusively in four studies, $[6,58,63,67]$ and both graft types were utilized in six studies. $[48,49,62,64,68,69]$ Two studies did not report graft type.[61, 66]

One study excluded patients with any previous history of knee surgery.[69] Two studies excluded patients who specifically had a previous history of ACLR $[6,48]$ and three excluded patients with a history of meniscectomy.[62, 63,67] Three studies included patients with ipsilateral partial meniscectomy[62] or contralateral ACL reconstruction.[66, 68] Nine studies[49, 58-61, 64, 65, 68, 70] did not provide information regarding patients' previous surgical history. Surgical details beyond graft type and fixation, including information regarding meniscectomy or meniscal repair, was stated in one study.[6] 
Concurrent meniscal repair during surgery was permitted in two studies $[6,67]$ but not in two others.[64, 68]

Each study defined athletic status based on patients' pre-injury competition level or Tegner activity level. Competitive athletes were generally defined as anyone participating in nonprofessional sports leagues locally, regionally or nationally. Recreational athletes were defined as anyone participating in sports who did not meet the definition of a competitive athlete. Ten studies included patients participating in at least recreational sports. $[6,49,60-$ $63,65,66,69,70]$ Two studies included only patients participating in competitive sports. $[58,68]$ Four studies did not report pre-injury athletic status.[59, 64, 66, 67]

\section{Patient Follow-up}

Patients were tracked for return to sport between six months and 7.9 years after ACLR. The most common re-evaluation timeframe was at one year post-surgery.[49, 58, 63-66, 68, 69] Other timeframes used were 6 months,[68] 1-2 years,[61] 2-3 years,[62, 63, 67, 70] 3-4 years, $[48,60]$ five years,[6] and eight years.[59]

\section{Return to Sport Outcomes}

Return to sport information was obtained using two methods: through patient self-report[48, $58,65,66,68-70]$ including the Tegner Activity Scale, $[6,49,61-64,67]$ and study-defined criteria.[59,60] In studies where patient self-report was used but not with the Tegner Activity Scale, patients compared their current sports participation frequency[65, 70] and/or competition level[ $48,58,65,66,68,70]$ to their pre-injury participation level. For studydefined criteria, Arvidsson et al.[59] grouped patients from I-IV, where Group I included patients with "no complaints, sports possible as normal" to Group IV which included those with "pronounced instability and pain made sports impossible." Barrett et al.[60] graded activity from I-IV, where Grade I included national or county level sports and Grade IV included those not participating in any sport. Though patients may not have returned to the same pre-injury sports, they classified these patients as having returned to their pre-injury level of sports if they rated their current and pre-injury activity levels the same at follow-up. At follow-up, an average of $50.7 \%$ of patients returned to pre-injury level of sports activity. $[6,48,58-60,62,63,68-70]$ Modified sports participation, defined as patients achieving a lesser activity level compared to their pre-injury level, was reported in $32.9 \%$ of patients and $17.2 \%$ of patients did not return to sports at all.[6, 58-60, 62, 63, 66, 70] Patient reported reasons for not returning to pre-injury sports participation included fear of re-injury, $[6,48$, $60,62,69,70]$ impaired knee function, $[48,70]$ social/family reasons, $[6,70]$ instability, $[6$, 69] pain, [62, 69] no motivation, [48] effusion,[69] muscle weakness,[69] and knee extension deficit.[62]

\section{Variables Associated with Return to Sport}

Variables Representing Knee Impairment and Function-The evidence reporting the association between knee impairment and function and return to sport is limited. Based on four level 4 studies and one level 2 study, weak evidence[54] supports associations between return to sport and higher post-operative quadriceps torque, $[59,69,70]$ less knee effusion[60,69] and a higher Marx Activity Score[62]. Based on two level 2 studies and one level 4 study, weak evidence[54] supports associations between return to sport and greater post-operative tibial rotation, [67] less pain[60, 69] and fewer episodes of instability.[69] Based on one level 2 study and four level 4 studies, weak evidence[54] indicates no association between return to sport and pre-operative quadriceps torque,[64] pre-operative anterior knee joint laxity,[64] post-operative anterior knee joint laxity,[60, 68, 69] preoperative knee extension ROM,[64] post-operative knee extension or flexion ROM,[69] or pre-injury activity level.[64] There is conflicting evidence for associations between return to 
sport and the IKDC subjective form score,[6, 62, 69] IKDC Grade,[6, 58, 62] post-operative hamstring torque,[59, 61] Lysholm Knee score[6, 61, 62] and post-operative LSI for single hop or crossover hop for distance.[58, 61, 68] Available raw data and between-group statistics for each study is presented in Table 2.

Psychological Variables-Studies utilized several standardized measures to assess psychological variables, including the Tampa Scale of Kinesiophobia (fear of movement or re-injury),[48, 65, 69] Anterior Cruciate Ligament-Return to Sport after Injury Scale (athletic confidence, emotions and risk appraisal),[66, 68] Psychovitality questionnaire (selfmotivation to return to sport),[62, 63] Knee Self-Efficacy Scale (evaluates beliefs about the ability to perform tasks),[49] Shortened Profile of Mood States (negative affect),[65] Pain Catastrophizing Scale (evaluates people's thoughts and feelings about pain)[65] and Emotional Responses of Athletes to Injury Questionnaire.[68]

Based on three level 2 and two level 4 studies, weak evidence[54] supports associations between return to sport and kinesiophobia[48, 65, 69] and athletic confidence.[66, 68] Based on one level 2 and one level 4 study, weak evidence[54] supports associations between return to sport and pre-operative knee self-efficacy[49] and pre-operative self-motivation. $[62,63]$ Weak evidence [54] exists indicating that emotional response to injury/surgery,[68] negative affect and pain catastrophizing[65] are not associated with return to sport.

Available raw data and between-group statistics are presented in Table 2 .

\section{DISCUSSION}

Surgery is commonly recommended for athletes with ACL tears wishing to return to their previous level of sports activity.[2] However, many of these athletes never return to their pre-injury level of play.[3,5] This review summarizes the literature on knee impairment, function and psychological variables associated with return to sport following ACLR. In this review, we broadly defined return to sport to include all possible definitions (any sport, the same sport and the same level in pre-injury sport) and at any post-surgical timeframe. A limited number of articles met our inclusion criteria. Many potentially relevant articles only included self-report of function as the primary outcome and were excluded. Although functional improvement is important, return to sport is often the main reason patients elect surgery.[2] Based on our review, weak evidence[54] exists suggesting that higher postoperative quadriceps strength, $[59,69,70]$ less knee effusion, [60, 69] lower pain, $[60,69]$ fewer episodes of instability,[69] greater tibial rotation ROM,[67] lower kinesiophobia,[48, $65,69]$ higher athletic confidence,[66, 68] higher pre-operative knee self-efficacy[49] and higher pre-operative self-motivation[62, 63] are associated with return to sport. Although post-surgical anterior knee joint laxity has been linked with patient satisfaction[71] and general knee function[72] following ACLR, there was insufficient evidence that anterior knee laxity influences return to sport.[60, 68, 69]

Return to sport criteria following ACLR includes various assessments of knee impairment and function. Recently, Barber-Westin and Noyes[10] reported the most commonly cited post-surgical return to play criteria included achieving specific LSI for quadriceps strength and hop testing, full knee ROM and no knee effusion. They also advocated for the inclusion of a drop-jump test, single-leg squat test to 90 degrees, assessment of knee laxity and examination of sports-specific drill performance. Thomeé et al.[9] recommended strength and hop test performance criteria utilizing both absolute values and between-limb comparisons prior to return to sport, and proposed criteria be adjusted according to type of sport patients are returning to (e.g. cutting/pivoting, recreational/competitive, contact/ noncontact). Our review supports including assessment of LSI for quadriceps strength and measurement of knee effusion. However, we found conflicting evidence to support the use 
of hop testing, and insufficient evidence to support using anterior knee joint laxity assessment or knee flexion and extension ROM in return to sports criteria following ACLR. Although functional testing, which traditionally evaluates differences between the surgical and non-surgical limb, is considered important to assess athletes' neuromuscular control and has been linked to better self-reported knee function,[73] only three studies examined the association between hop testing and return to sport.[58, 61, 68] Although two studies found no association between LSI on the single hop for distance[61, 68] or crossover hop for distance[61, 68] and return to sport, Ardern et al.[58] noted that a LSI $285 \%$ on both hop tests significantly increased the likelihood of return to pre-injury level of sports participation. Baltaci et al.[61] also studied the triple hop for distance and found no association with return to sport. Additional studies investigating the relationship between hop testing and return to sport are needed for more definitive conclusions.

General return to sport criteria does not include assessments of psychological variables, yet evidence exists for their inclusion. Fear of re-injury is a frequently cited reason patients do not return to pre-injury level of sport[46] and may relate to some athletes' confidence in their ability to safely return to sport following surgery. In this review, lower athletic confidence was associated with decreased likelihood of return to sport.[66, 68] Psychological variables such as fear of re-injury[48, 65, 69] and reduced athletic confidence[66, 68] may explain why some athletes without physical or functional impairments choose not to return to sport. [45] Physical and psychological readiness to return to sport following injury do not always coincide,[43] so techniques addressing fear and athletic confidence may need to be incorporated during rehabilitation. Patients receiving pre-surgical education by patients who have completed their post-ACLR rehabilitation, known as "modeling," demonstrate higher rehabilitation self-efficacy and earlier functional achievements six weeks post-ACLR.[74] In the post-lumbar fusion population, combined psychomotor training to improve movement patterns and address maladaptive psychological behaviors decreases kinesiophobia, improves self-efficacy and decreases functional disability up to three years post-surgery.[75] The short-and long-term effectiveness of modeling and psychomotor training on return to sport in the post-ACLR population warrants further attention.

For this review, we broadly defined return to pre-injury sport to include the same level of sport, whether or not participation in the actual pre-injury sport was achieved, at any timeframe post-surgery. Overall, $50.7 \%$ of patients returned to their pre-injury level of sports, $[6,48,58-60,62,63,68-70]$ which is lower than previously published reviews.[3, 46] At two years post-surgery, two separate reviews reported 63-79\% return to pre-injury sports participation.[3, 46] In contrast to these reviews, post-surgical follow-up in this review ranged from one year to eight years post-surgery, which may have influenced reported rates. Additionally, ten studies in this review included recreational athletes, [6, 49, $60-63,65,66,69,70]$ but the athletic participation levels in previous reviews[3, 46] was not described. Athletes participating at higher competitive sports levels have shorter physical recoveries post-surgery[76] and professional athletes' motivation to return to pre-injury level of sport is likely higher than non-professional athletes. However, compared to recreational athletes, professional athletes' drive to return to play may yield greater negative psychological responses following injury and/or surgery, which may also affect return to sport. Future research addressing the influence of the level of athletic participation on return to sports rates is needed.

There are some limitations to this review. First, relevant articles may have been missed. In an attempt to capture all relevant articles, multiple databases were searched with the aid of a reference librarian and no limitation on publication year was applied. Only one exclusion criterion of no concomitant ligamentous surgery or microfracture surgery was used. This did not affect the number of studies examined, as studies including concomitant ligamentous 
surgery or microfracture surgery had already been eliminated for not meeting the inclusion criteria, including analysis between variables of interest and return to sport or utilizing a specific return to sport measure. Second, we restricted our search to articles published in English, which may have limited our results. Resources to translate foreign publications were not available. Additionally, we included articles using the Tegner Activity Scale, which categorizes individuals who are playing sport as well as those who are not. By not differentiating between sports and work activities, articles utilizing this measure may not accurately report actual return to sport. We chose to include these articles because they made attempts to quantify regular physical activity levels, as opposed to articles which were excluded because they used scales that only identified potential activity levels. Finally, four studies $[59,64,66,67]$ did not indicate patients' pre-injury sports participation. It is possible these patients were not participating in sports before surgery so returning to sport was not a relevant outcome. This may have affected the accuracy of our return to sport analysis.

Many studies provided only Level 4 evidence and all studies were rated as having a high risk of bias. Although RCTs are ideal, prospective cohort designs including assessment of the multiple variables thought to be associated with return to sport, such as age, gender and time since surgery, would be appropriate. Fourteen studies had 100 patients or less[6, 48, 49, 59-65, 67-70] and of these, six had less than 50 patients. $[49,60,61,65,67,70]$ With relatively small sample sizes, it is possible the magnitude of the results was overstated. Studies with larger cohorts are needed to clarify these relationships. The type of postoperative rehabilitation, such as accelerated versus conservative, may influence patients' ability to return to sport. Patients' post-operative rehabilitation course was reported in varying detail in only ten studies, $[6,58,60,63,64,66-70]$ making it difficult to critically examine all variables that may be related to patient outcomes. Only four prospective cohort studies accounted for potential confounders to surgical outcomes, such as age, gender, time since surgery and body mass index.[49, 64-66] These studies did not find significantly different results compared to those not statistically adjusting for these confounders, but the strength of associations reported in this review may have been altered if all studies performed these analyses. Although several studies included documentation of anterior knee laxity $[62,63,67,70]$ and ROM, $[60,61,63,68]$ their association with return to sport was not examined. Four articles examining these relationships found no association between return to sport and laxity[60, 64, 68, 69] or ROM[64, 69] but these conclusions may have been altered if the associations were consistently analyzed across all studies. Finally, genderrelated differences in return to sport may exist but were not explored in any study in this review. Ardern et al.[58] reported men were more likely than women to attempt full competition in their pre-injury sport one year post-surgery and Noojin et al.[77] reported that males scored higher on the Tegner Activity Scale than females three years post-surgery. However, Ferrari et al.[78] found no gender difference in Tegner scores 4.5 years postACLR. These limitations highlight the need for further studies in this area.

The influence of multiple variables representing knee impairment, function, and psychological status on return to sport following ACLR has been investigated. Commonly utilized post-surgical return to play criteria include evaluation of knee impairments such as quadriceps strength and effusion that, in this review, were weakly[54] associated with return to sport. Evidence was lacking to definitively support associations between return to sport and other variables representing knee impairments and function, such as knee joint laxity and hop testing. The ability of athletes to return to their pre-injury level of sport following surgery is likely multifactorial, but currently there is not enough evidence to make strong recommendations about current return to play criteria. Greater attention should be placed on the effectiveness of these objective criteria in accurately identifying when patients can safely return to pre-injury activity levels. Additionally, including psychological criteria in return to sports guidelines is likely warranted. Future research should include larger randomized 
studies that investigate multiple variables representing knee impairment, function and psychological status, their interactions and return to play.

\section{Acknowledgments}

The authors would like to acknowledge Kim Lipsey, MLS, member of the Health Information Resources division at Washington University's Bernard Becker Medical Library, for her assistance with the literature search.

Funding Statement: This work was supported by the National Center for Research Resources (NCRR), a component of the National Institutes of Health (NIH) and NIH Roadmap for Medical Research Grant Number UL1 RR024992. Dr. Racette was supported by K24 NS060825 and UL1 TR000448 from the National Center for Advancing Translational Sciences (NCATS) of the National Institutes of Health (NIH). Dr. Harris-Hayes was supported by the National Center for Medical Rehabilitation Research, National Institute of Child Health and Human Development Grant K23 HD067343.

Competing Interest Statement: All authors have completed the Unified Competing Interest form at www.icmje.org/coi_disclosure.pdf (available on request from the corresponding author) and declare that all authors had financial support through the NCRR for the statistical analyses only for this manuscript. MHH had financial support from the National Center for Medical Rehabilitation Research, National Institute of Child Health and Human Development for the submitted work. BAR receives research funding from the National Institute of Health SC and SK have no other financial relationships with any organizations that might have an interest in the submitted work in the previous 3 years; no other relationships or activities that could appear to have influenced the submitted work.

\section{Appendix}




\begin{tabular}{|c|c|c|c|c|c|c|c|c|c|c|}
\hline 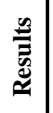 & $\pi$ & - & $\frac{\sqrt{\tilde{y}}}{\sqrt{2}}$ & $a$ & $\begin{array}{l}\text { 売 } \\
g \\
g\end{array}$ & 0 & o & ナ & 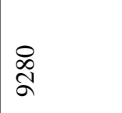 & - \\
\hline 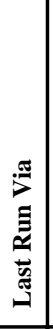 & 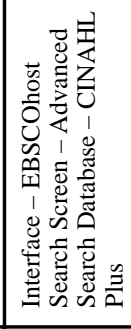 & 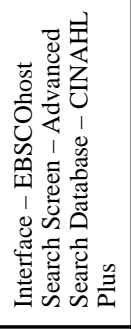 & 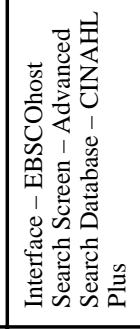 & 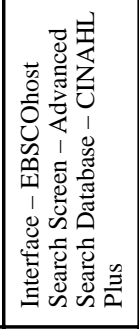 & 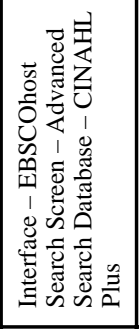 & 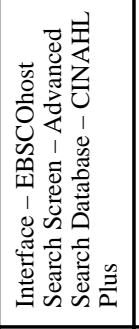 & 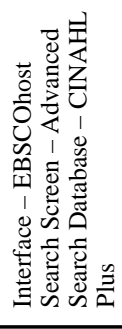 & 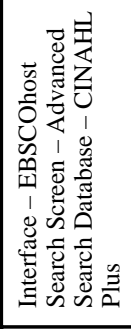 & 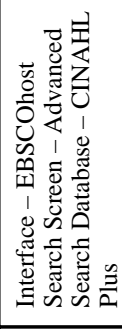 & 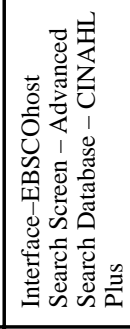 \\
\hline 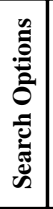 & 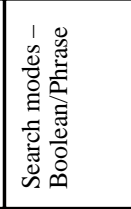 & 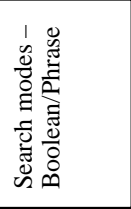 & 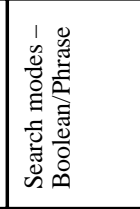 & 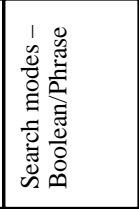 & 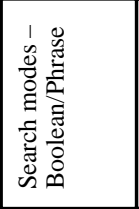 & 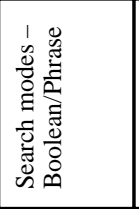 & 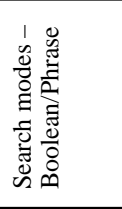 & 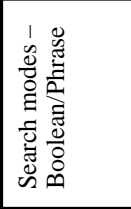 & 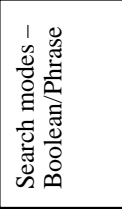 & 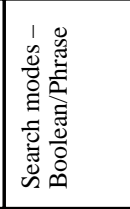 \\
\hline & 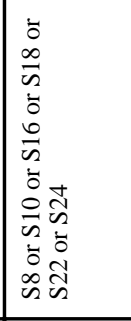 & 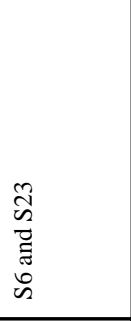 & 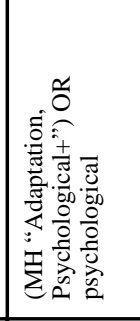 & $\begin{array}{l}\bar{v} \\
\bar{v} \\
\overline{\tilde{w}} \\
\tilde{\tilde{w}}\end{array}$ & 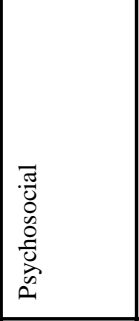 & 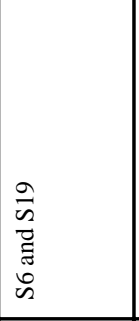 & 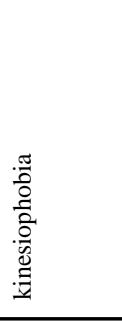 & $\begin{array}{l}n \\
\bar{n} \\
\bar{n} \\
\bar{w} \\
\infty\end{array}$ & 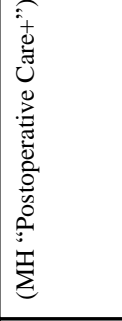 & 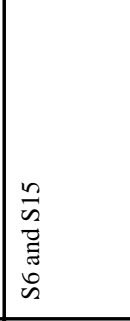 \\
\hline 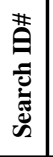 & $\ddot{d}$ & $\underset{\widetilde{U}}{\mathbb{U}}$ & 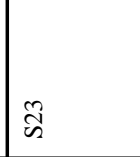 & $\tilde{\pi}$ & $\overline{\tilde{N}}$ & ஸे & $\frac{\partial}{\tilde{n}}$ & $\frac{\infty}{n}$ & $\stackrel{\circ}{\omega}$ & $\frac{\mathscr{L}}{\omega}$ \\
\hline
\end{tabular}




\begin{tabular}{|c|c|c|c|c|c|c|c|c|c|c|c|c|}
\hline 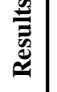 & $\begin{array}{l}\mathscr{D} \\
2 \\
\alpha\end{array}$ & 0 & 总 & - & $\stackrel{0}{7}$ & $\infty$ & $\vec{\Delta}$ & $\stackrel{\infty}{-}$ & $\stackrel{\overline{\mathrm{S}}}{=}$ & $\vec{n}$ & $\begin{array}{l}\infty \\
\stackrel{0}{0} \\
\stackrel{0}{0}\end{array}$ & $\vec{\infty}$ \\
\hline 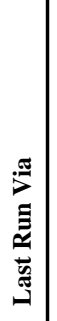 & 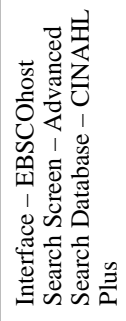 & 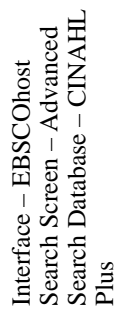 & 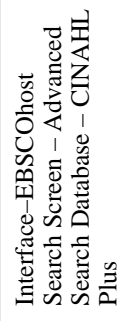 & 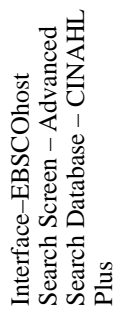 & 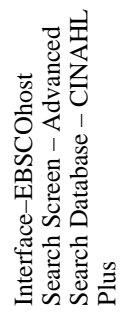 & 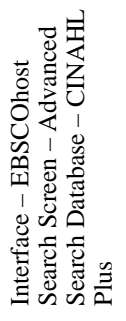 & 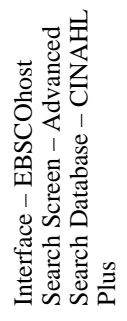 & 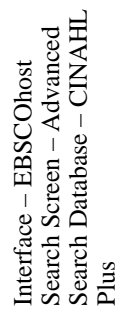 & 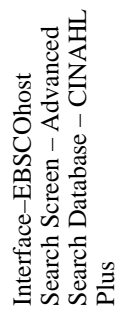 & 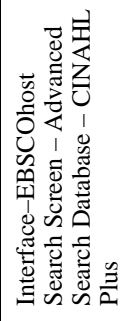 & 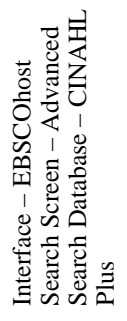 & 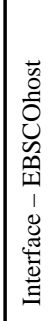 \\
\hline 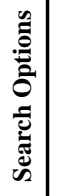 & 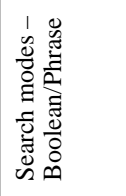 & 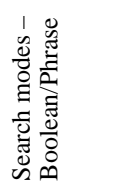 & 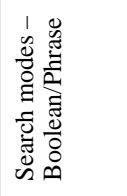 & 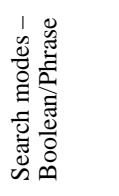 & 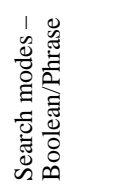 & 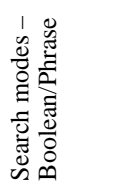 & 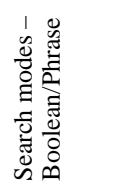 & 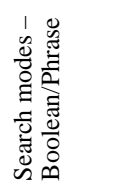 & 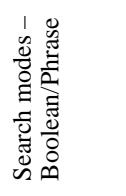 & 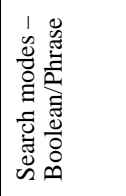 & 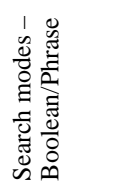 & $>$ \\
\hline 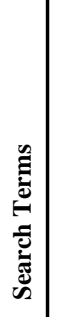 & 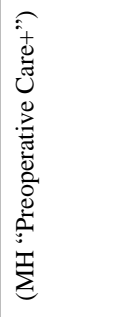 & $\begin{array}{l}\frac{m}{n} \\
\tilde{n} \\
\tilde{\Xi} \\
\stackrel{5}{n}\end{array}$ & 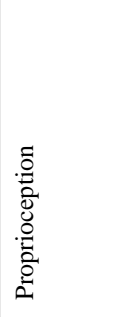 & 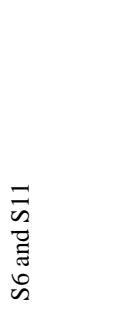 & 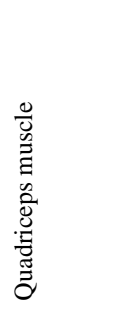 & $\begin{array}{l}\text { के } \\
\text { ज्ञ } \\
\text { ज्ञ } \\
\text { in }\end{array}$ & 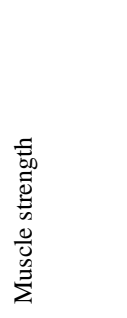 & 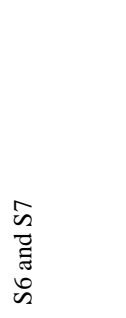 & 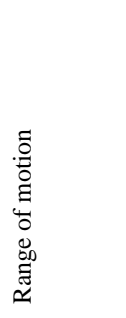 & 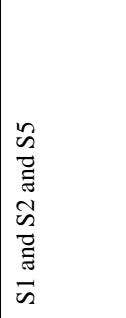 & 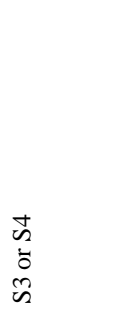 & 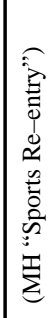 \\
\hline 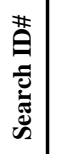 & $\frac{n}{n}$ & $\frac{\Delta}{n}$ & $\frac{m}{n}$ & $\frac{N}{n}$ & $\overrightarrow{\bar{n}}$ & $\frac{O}{n}$ & ஜे & $\stackrel{\infty}{\infty}$ & $\hat{n}$ & ஜ & $n$ & 芯 \\
\hline
\end{tabular}




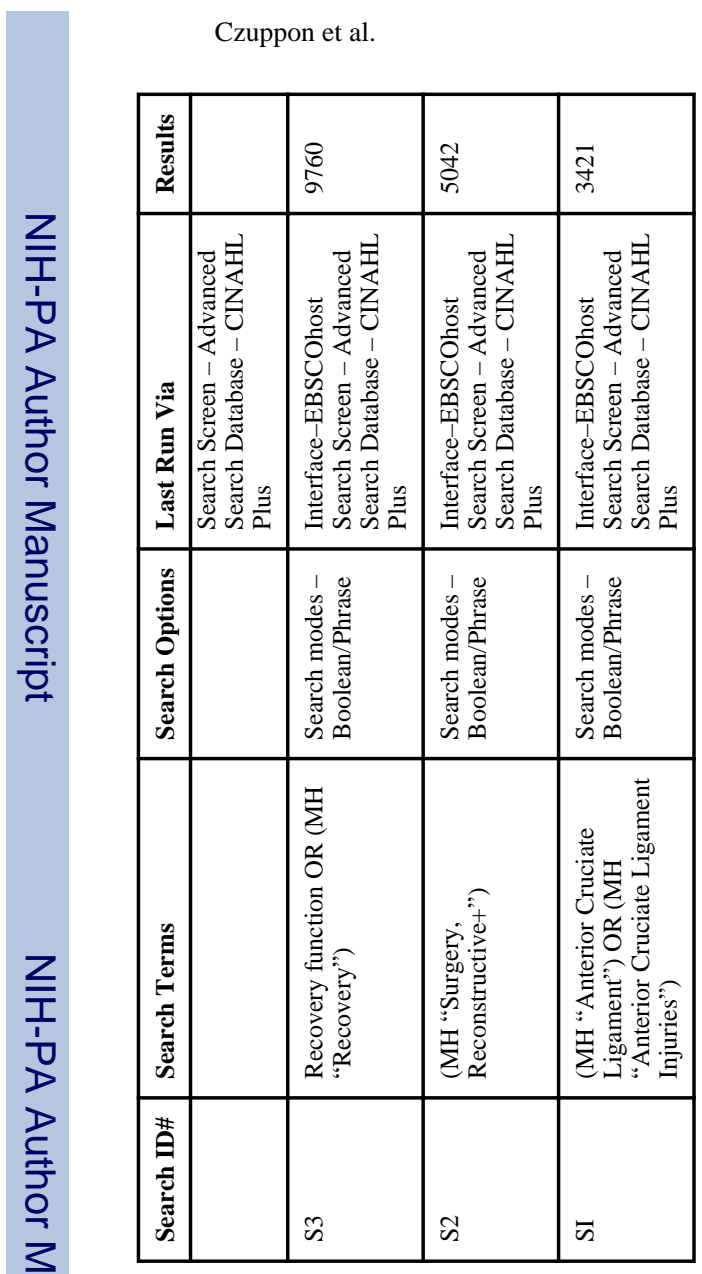

Br J Sports Med. Author manuscript; available in PMC 2015 March 01. 


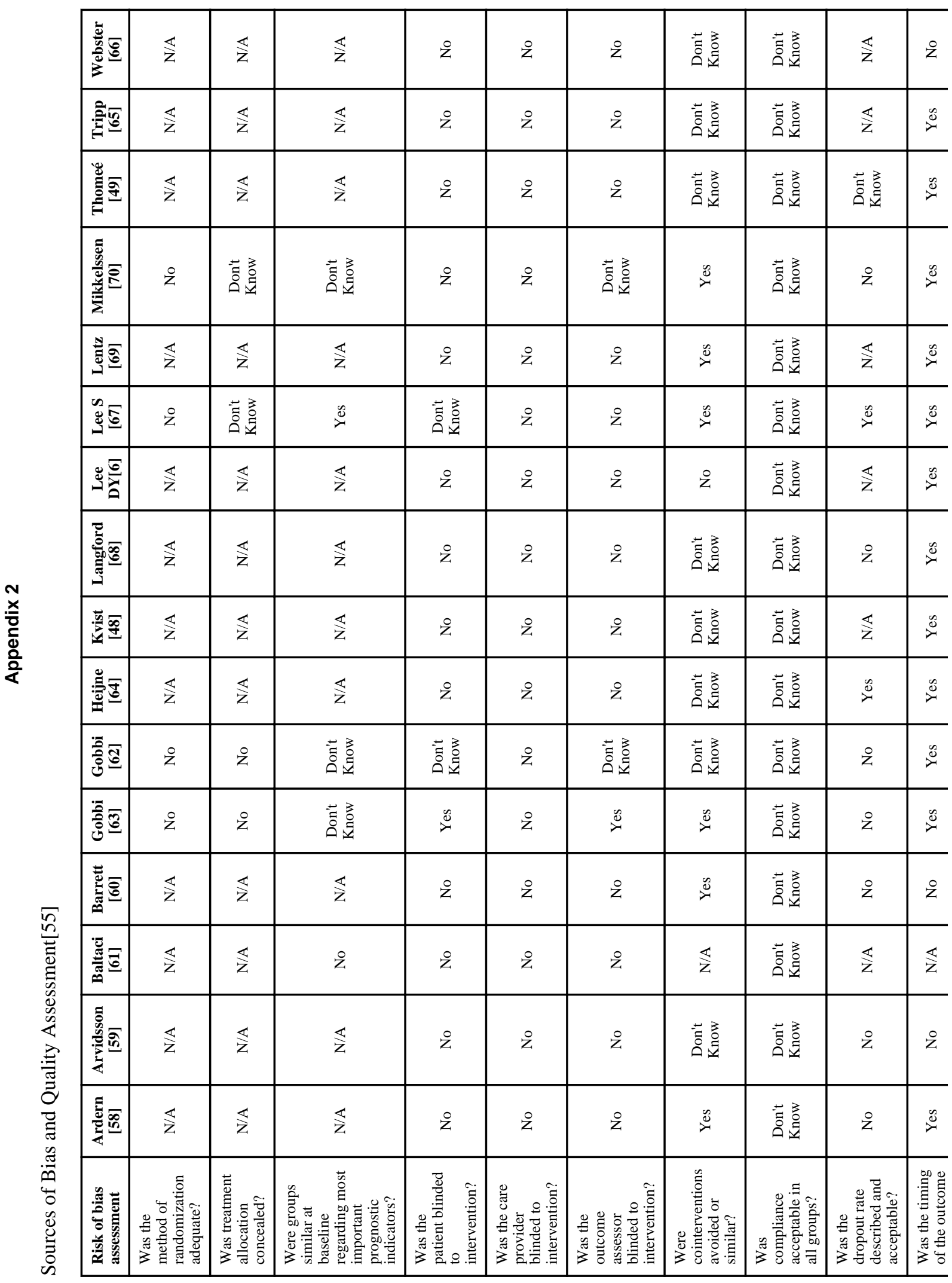




\begin{tabular}{|c|c|c|c|}
\hline 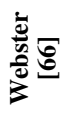 & & $\overleftrightarrow{\Sigma}$ & 咅 \\
\hline 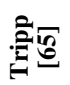 & & $\overleftrightarrow{\mathrm{z}}$ & $\begin{array}{l}\frac{5}{50} \\
0.0\end{array}$ \\
\hline 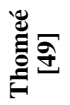 & & $\overleftrightarrow{\mathrm{z}}$ & 总 \\
\hline 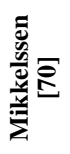 & & $\stackrel{\infty}{\infty}$ & 总 \\
\hline 产 & & $\overleftrightarrow{\mathrm{z}}$ & $\begin{array}{l}\frac{5}{.00} \\
: \pm\end{array}$ \\
\hline 约 & & $\stackrel{2}{z}$ & 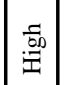 \\
\hline פ & & $\overleftrightarrow{\mathbb{Z}}$ & $\begin{array}{l}\frac{7}{b 0} \\
:=1\end{array}$ \\
\hline 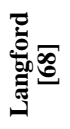 & & $\overleftrightarrow{\nwarrow}$ & $\frac{\vec{c}}{3}$ \\
\hline 产交 & & $\overleftrightarrow{z}$ & 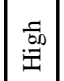 \\
\hline 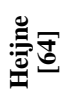 & & $\overleftrightarrow{\mathrm{z}}$ & $\mid \begin{array}{l}\frac{5}{60} \\
: \pm 0\end{array}$ \\
\hline 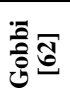 & & $\overbrace{\nu}^{\infty}$ & 窇 \\
\hline 言 & & $\stackrel{0}{\circ}$ & $\begin{array}{l}5 \\
.50 \\
: 7\end{array}$ \\
\hline 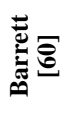 & & $\overleftrightarrow{\mathrm{z}}$ & $\begin{array}{l}\frac{5}{50} \\
: 3\end{array}$ \\
\hline 䔍 & & $\overleftrightarrow{z}$ & 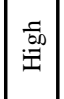 \\
\hline 旋 & & $\overleftrightarrow{\mathrm{z}}$ & $\frac{-5}{.00}$ \\
\hline 总 & & $\overleftrightarrow{Z}$ & $\begin{array}{l}\frac{5}{.00} \\
: \pm\end{array}$ \\
\hline 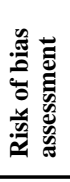 & 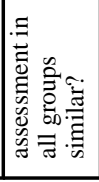 & 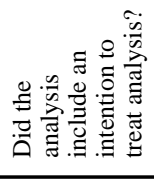 & 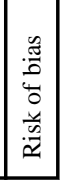 \\
\hline
\end{tabular}

Br J Sports Med. Author manuscript; available in PMC 2015 March 01. 


\section{REFERENCES}

1. Cohen SB, Sekiya JK. Allograft safety in anterior cruciate ligament reconstruction. Clin Sports Med. 2007; 26(4):597-605. [PubMed: 17920955]

2. Marx RG, Jones EC, Angel M, et al. Beliefs and attitudes of members of the American Academy of Orthopaedic Surgeons regarding the treatment of anterior cruciate ligament injury. Arthroscopy. 2003; 19(7):762-770. [PubMed: 12966385]

3. Lewis PB, Parameswaran AD, Rue JP, et al. Systematic review of single-bundle anterior cruciate ligament reconstruction outcomes: a baseline assessment for consideration of double-bundle techniques. Am J Sports Med. 2008; 36(10):2028-2036. [PubMed: 18757764]

4. Pinczewski LA, Deehan DJ, Salmon LJ, et al. A five-year comparison of patellar tendon versus four-strand hamstring tendon autograft for arthroscopic reconstruction of the anterior cruciate ligament. Am J Sports Med. 2002; 30(4):523-536. [PubMed: 12130407]

5. Salmon L, Russell V, Musgrove T, et al. Incidence and risk factors for graft rupture and contralateral rupture after anterior cruciate ligament reconstruction. Arthroscopy. 2005; 21(8):948957. [PubMed: 16084292]

6. Lee DY, Karim SA, Chang HC. Return to sports after anterior cruciate ligament reconstruction - a review of patients with minimum 5-year follow-up. Ann Acad Med Singapore. 2008; 37(4):273278. [PubMed: 18461210]

7. Brophy RH, Schmitz L, Wright RW, et al. Return to play and future ACL injury risk after ACL reconstruction in soccer athletes from the Multicenter Orthopaedic Outcomes Network (MOON) group. Am J Sports Med. 2012; 40(11):2517-2522. [PubMed: 23002201]

8. Kvist J. Rehabilitation following anterior cruciate ligament injury: current recommendations for sports participation. Sports Med. 2004; 34(4):269-280. [PubMed: 15049718]

9. Thomee R, Kaplan Y, Kvist J, et al. Muscle strength and hop performance criteria prior to return to sports after ACL reconstruction. Knee Surg Sports Traumatol Arthrosc. 2011; 19(11):1798-1805. [PubMed: 21932078]

10. Barber-Westin SD, Noyes FR. Objective criteria for return to athletics after anterior cruciate ligament reconstruction and subsequent reinjury rates: a systematic review. Phys Sportsmed. 2011; 39(3):100-110. [PubMed: 22030946]

11. Barber-Westin SD, Noyes FR. Factors Used to Determine Return to Unrestricted Sports Activities After Anterior Cruciate Ligament Reconstruction. Arthroscopy-the Journal of Arthroscopic and Related Surgery. 2011; 27(12):1697-1705.

12. Aune AK, Holm I, Risberg MA, et al. Four-strand hamstring tendon autograft compared with patellar tendon-bone autograft for anterior cruciate ligament reconstruction. A randomized study with two-year follow-up. Am J Sports Med. 2001; 29(6):722-728. [PubMed: 11734484]

13. Beynnon BD, Johnson RJ, Fleming BC, et al. Anterior cruciate ligament replacement: comparison of bone-patellar tendon-bone grafts with two-strand hamstring grafts. A prospective, randomized study. J Bone Joint Surg Am. 2002; 84-A(9):1503-1513. [PubMed: 12208905]

14. Drogset JO, Grontvedt T, Tegnander A. Endoscopic reconstruction of the anterior cruciate ligament using bone-patellar tendon-bone grafts fixed with bioabsorbable or metal interference screws: a prospective randomized study of the clinical outcome. Am J Sports Med. 2005; 33(8): 1160-1165. [PubMed: 16000666]

15. Mascarenhas R, Tranovich M, Karpie JC, et al. Patellar tendon anterior cruciate ligament reconstruction in the high-demand patient: evaluation of autograft versus allograft reconstruction. Arthroscopy. 2010; 26(9 Suppl):S58-66. [PubMed: 20810093]

16. Sajovic M, Strahovnik A, Komadina R, et al. The effect of graft choice on functional outcome in anterior cruciate ligament reconstruction. Int Orthop. 2008; 32(4):473-478. [PubMed: 17431619]

17. Siebold R, Webster KE, Feller JA, et al. Anterior cruciate ligament reconstruction in females: a comparison of hamstring tendon and patellar tendon autografts. Knee Surg Sports Traumatol Arthrosc. 2006; 14(11):1070-1076. [PubMed: 16758236]

18. Shelbourne KD, Klotz C. What I have learned about the ACL: utilizing a progressive rehabilitation scheme to achieve total knee symmetry after anterior cruciate ligament reconstruction. J Orthop Sci. 2006; 11(3):318-325. [PubMed: 16721538] 
19. Drogset JO, Grontvedt T. Anterior cruciate ligament reconstruction with and without a ligament augmentation device : results at 8-Year follow-up. Am J Sports Med. 2002; 30(6):851-856. [PubMed: 12435652]

20. Drogset JO, Strand T, Uppheim G, et al. Autologous patellar tendon and quadrupled hamstring grafts in anterior cruciate ligament reconstruction: a prospective randomized multicenter review of different fixation methods. Knee Surg Sports Traumatol Arthrosc. 2010; 18(8):1085-1093. [PubMed: 19956928]

21. Henriksson M, Rockborn P, Good L. Range of motion training in brace vs. plaster immobilization after anterior cruciate ligament reconstruction: a prospective randomized comparison with a 2-year follow-up. Scand J Med Sci Sports. 2002; 12(2):73-80. [PubMed: 12121424]

22. Isberg J, Faxen E, Brandsson $\mathrm{S}$, et al. Early active extension after anterior cruciate ligament reconstruction does not result in increased laxity of the knee. Knee Surg Sports Traumatol Arthrosc. 2006; 14(11):1108-1115. [PubMed: 16955299]

23. Moller E, Forssblad M, Hansson L, et al. Bracing versus nonbracing in rehabilitation after anterior cruciate ligament reconstruction: a randomized prospective study with 2-year follow-up. Knee Surg Sports Traumatol Arthrosc. 2001; 9(2):102-108. [PubMed: 11354851]

24. Poehling GG, Curl WW, Lee CA, et al. Analysis of outcomes of anterior cruciate ligament repair with 5-year follow-up: allograft versus autograft. Arthroscopy. 2005; 21(7):774-785. [PubMed: 16012489]

25. Zaffagnini S, Bruni D, Marcheggiani Muccioli GM, et al. Single-bundle patellar tendon versus non-anatomical double-bundle hamstrings ACL reconstruction: a prospective randomized study at 8-year minimum follow-up. Knee Surg Sports Traumatol Arthrosc. 2011; 19(3):390-397. [PubMed: 20668835]

26. Zaffagnini S, Bruni D, Russo A, et al. ST/G ACL reconstruction: double strand plus extra-articular sling vs double bundle, randomized study at 3-year follow-up. Scand J Med Sci Sports. 2008; 18(5):573-581. [PubMed: 18208432]

27. Keays SL, Bullock-Saxton JE, Newcombe P, et al. The relationship between knee strength and functional stability before and after anterior cruciate ligament reconstruction. J Orthop Res. 2003; 21(2):231-237. [PubMed: 12568953]

28. Kobayashi A, Higuchi H, Terauchi M, et al. Muscle performance after anterior cruciate ligament reconstruction. Int Orthop. 2004; 28(1):48-51. [PubMed: 12942198]

29. Bush-Joseph CA, Hurwitz DE, Patel RR, et al. Dynamic function after anterior cruciate ligament reconstruction with autologous patellar tendon. Am J Sports Med. 2001; 29(1):36-41. [PubMed: 11206254]

30. Hamilton RT, Shultz SJ, Schmitz RJ, et al. Triple-hop distance as a valid predictor of lower limb strength and power. J Athl Train. 2008; 43(2):144-151. [PubMed: 18345338]

31. Noyes FR, Barber SD, Mangine RE. Abnormal lower limb symmetry determined by function hop tests after anterior cruciate ligament rupture. Am J Sports Med. 1991; 19(5):513-518. [PubMed: 1962720]

32. Ostenberg A, Roos E, Ekdahl C, et al. Isokinetic knee extensor strength and functional performance in healthy female soccer players. Scand J Med Sci Sports. 1998; 8(5 Pt 1):257-264. [PubMed: 9809383]

33. Sekiya I, Muneta T, Ogiuchi T, et al. Significance of the single-legged hop test to the anterior cruciate ligament-reconstructed knee in relation to muscle strength and anterior laxity. Am J Sports Med. 1998; 26(3):384-388. [PubMed: 9617400]

34. Wilk KE, Romaniello WT, Soscia SM, et al. The Relationship between Subjective Knee Scores, Isokinetic Testing, and Functional Testing in the Acl-Reconstructed Knee. J Orthop Sport Phys. 1994; 20(2):60-73.

35. Barrett GR, Luber K, Replogle WH, et al. Allograft anterior cruciate ligament reconstruction in the young, active patient: Tegner activity level and failure rate. Arthroscopy. 2010; 26(12):15931601. [PubMed: 20952145]

36. Marcacci M, Zaffagnini S, Giordano G, et al. Anterior cruciate ligament reconstruction associated with extra-articular tenodesis: A prospective clinical and radiographic evaluation with 10- to 13year follow-up. Am J Sports Med. 2009; 37(4):707-714. [PubMed: 19193599] 
37. Wagner M, Kaab MJ, Schallock J, et al. Hamstring tendon versus patellar tendon anterior cruciate ligament reconstruction using biodegradable interference fit fixation - A prospective matchedgroup analysis. Am J Sport Med. 2005; 33(9):1327-1336.

38. Zaffagnini S, Marcacci M, Lo Presti M, et al. Prospective and randomized evaluation of ACL reconstruction with three techniques: a clinical and radiographic evaluation at 5 years follow-up. Knee Surg Sports Traumatol Arthrosc. 2006; 14(11):1060-1069. [PubMed: 16909301]

39. Fitzgerald GK, Lephart SM, Hwang JH, et al. Hop tests as predictors of dynamic knee stability. J Orthop Sports Phys Ther. 2001; 31(10):588-597. [PubMed: 11665746]

40. Delahunt E, Sweeney L, Chawke M, et al. Lower limb kinematic alterations during drop vertical jumps in female athletes who have undergone anterior cruciate ligament reconstruction. J Orthop Res. 2012; 30(1):72-78. [PubMed: 21809380]

41. Paterno MV, Ford KR, Myer GD, et al. Limb asymmetries in landing and jumping 2 years following anterior cruciate ligament reconstruction. Clin J Sport Med. 2007; 17(4):258-262. [PubMed: 17620778]

42. Smith FW, Rosenlund EA, Aune AK, et al. Subjective functional assessments and the return to competitive sport after anterior cruciate ligament reconstruction. Br J Sports Med. 2004; 38(3): 279-284. [PubMed: 15155426]

43. Podlog L, Eklund RC. The psychosocial aspects of a return to sport following serious injury: A review of the literature from a self-determination perspective. Psychol Sport Exerc. 2007; 8(4): 535-566.

44. Johnston LH, Carroll D. The context of emotional responses to athletic injury: A qualitative analysis. J Sport Rehabil. 1998; 7(3):206-220.

45. Ardern CL, Taylor NF, Feller JA, et al. Psychological responses matter in returning to preinjury level of sport after anterior cruciate ligament reconstruction surgery. Am J Sports Med. 2013; 41(7):1549-1558. [PubMed: 23733635]

46. Ardern CL, Webster KE, Taylor NF, et al. Return to sport following anterior cruciate ligament reconstruction surgery: a systematic review and meta-analysis of the state of play. Br J Sports Med. 2011; 45(7):596-606. [PubMed: 21398310]

47. Chmielewski TL, Jones D, Day T, et al. The association of pain and fear of movement/reinjury with function during anterior cruciate ligament reconstruction rehabilitation. J Orthop Sports Phys Ther. 2008; 38(12):746-753. [PubMed: 19047767]

48. Kvist J, Ek A, Sporrstedt K, et al. Fear of re-injury: a hindrance for returning to sports after anterior cruciate ligament reconstruction. Knee Surg Sport Tr A. 2005; 13(5):393-397.

49. Thomee P, Wahrborg P, Borjesson M, et al. Self-efficacy of knee function as a pre-operative predictor of outcome 1 year after anterior cruciate ligament reconstruction. Knee Surg Sports Traumatol Arthrosc. 2008; 16(2):118-127. [PubMed: 18034333]

50. Thomee P, Wahrborg P, Borjesson M, et al. Self-efficacy, symptoms and physical activity in patients with an anterior cruciate ligament injury: a prospective study. Scand J Med Sci Sports. 2007; 17(3):238-245. [PubMed: 16774652]

51. Nyland J, Cottrell B, Harreld K, et al. Self-reported outcomes after anterior cruciate ligament reconstruction: an internal health locus of control score comparison. Arthroscopy. 2006; 22(11): 1225-1232. [PubMed: 17084301]

52. Nyland J, Johnson DL, Caborn DN, et al. Internal health status belief and lower perceived functional deficit are related among anterior cruciate ligament-deficient patients. Arthroscopy. 2002; 18(5):515-518. [PubMed: 11987063]

53. Moher D, Liberati A, Tetzlaff J, et al. Preferred reporting items for systematic reviews and metaanalyses: the PRISMA statement. BMJ. 2009; 339:b2535. [PubMed: 19622551]

54. Logerstedt DS, Snyder-Mackler L, Ritter RC, et al. Knee stability and movement coordination impairments: knee ligament sprain. J Orthop Sports Phys Ther. 2010; 40(4):A1-A37.

55. van Tulder M, Furlan A, Bombardier C, et al. Updated method guidelines for systematic reviews in the Cochrane Collaboration Back Review Group. Spine (Phila Pa 1976). 2003; 28(12):1290-1299. [PubMed: 12811274] 
56. van Tulder MW, Suttorp M, Morton S, et al. Empirical Evidence of an Association Between Internal Validity and Effect Size in Randomized Controlled Trials of Low-Back Pain. Spine (Phila Pa 1976). 2009; 34(16):1685-1692. [PubMed: 19770609]

57. Centre for Evidence Based Medicine. CEBM (Centre for Evidence-Based Medicine) Levels of Evidence. 2011. http://www.cebm.net/index.aspx?o=5653

58. Ardern CL, Webster KE, Taylor NF, et al. Return to the Preinjury Level of Competitive Sport After Anterior Cruciate Ligament Reconstruction Surgery Two-thirds of Patients Have Not Returned by 12 Months After Surgery. Am J Sport Med. 2011; 39(3):538-543.

59. Arvidsson I, Eriksson E, Haggmark T, et al. Isokinetic thigh muscle strength after ligament reconstruction in the knee joint: results from a 5-10 year follow-up after reconstructions of the anterior cruciate ligament in the knee joint. Int J Sports Med. 1981; 2(1):7-11. [PubMed: 7333737]

60. Barrett DS, Mackenney RP. MacIntosh-Jones reconstruction for the unstable knee. Injury. 1991; 22(4):282-286. [PubMed: 1937723]

61. Baltaci G, Yilmaz G, Atay AO. The outcomes of anterior cruciate ligament reconstructed and rehabilitated knees versus healthy knees: a functional comparison. Acta Orthop Traumatol Turc. 2012; 46(3):186-195. [PubMed: 22659635]

62. Gobbi A, Francisco R. Factors affecting return to sports after anterior cruciate ligament reconstruction with patellar tendon and hamstring graft: a prospective clinical investigation. Knee Surg Sports Traumatol Arthrosc. 2006; 14(10):1021-1028. [PubMed: 16496124]

63. Gobbi A, Mahajan V, Karnatzikos G, et al. Single- versus Double-bundle ACL Reconstruction: Is There Any Difference in Stability and Function at 3-year Followup? Clin Orthop Relat R. 2012; 470(3):824-834.

64. Heijne A, Ang BO, Werner S. Predictive factors for 12-month outcome after anterior cruciate ligament reconstruction. Scand J Med Sci Sports. 2009; 19(6):842-849. [PubMed: 19508651]

65. Tripp DA, Stanish W, Ebel-Lam A, et al. Fear of reinjury, negative affect, and catastrophizing predicting return to sport in recreational athletes with anterior cruciate ligament injuries at 1 year postsurgery. Rehabil Psychol. 2007; 52(1):74-81.

66. Webster KE, Feller JA, Lambros C. Development and preliminary validation of a scale to measure the psychological impact of returning to sport following anterior cruciate ligament reconstruction surgery. Phys Ther Sport. 2008; 9(1):9-15. [PubMed: 19083699]

67. Lee S, Kim H, Jang J, et al. Comparison of anterior and rotatory laxity using navigation between single- and double-bundle ACL reconstruction: prospective randomized trial. Knee Surg Sport Tr A. 2012; 20(4):752-761.

68. Langford JL, Webster KE, Feller JA. A prospective longitudinal study to assess psychological changes following anterior cruciate ligament reconstruction surgery. Br J Sports Med. 2009; 43(5): 377-378. [PubMed: 19019910]

69. Lentz TA, Zeppieri G, Tillman SM, et al. Return to Preinjury Sports Participation Following Anterior Cruciate Ligament Reconstruction: Contributions of Demographic, Knee Impairment, and Self-report Measures. J Orthop Sport Phys. 2012; 42(11):893-901.

70. Mikkelsen C, Werner S, Eriksson E. Closed kinetic chain alone compared to combined open and closed kinetic chain exercises for quadriceps strengthening after anterior cruciate ligament reconstruction with respect to return to sports: a prospective matched follow-up study. Knee Surg Sports Traumatol Arthrosc. 2000; 8(6):337-342. [PubMed: 11147151]

71. Kocher MS, Steadman JR, Briggs K, et al. Determinants of patient satisfaction with outcome after anterior cruciate ligament reconstruction. J Bone Joint Surg Am. 2002; 84-A(9):1560-1572. [PubMed: 12208912]

72. Johnson RJ, Eriksson E, Haggmark T, et al. Five- to ten-year follow-up evaluation after reconstruction of the anterior cruciate ligament. Clin Orthop Relat Res. 1984; 183:122-140. [PubMed: 6365386]

73. Logerstedt D, Grindem H, Lynch A, et al. Single-Legged Hop Tests as Predictors of Self-Reported Knee Function After Anterior Cruciate Ligament Reconstruction The Delaware-Oslo ACL Cohort Study. Am J Sport Med. 2012; 40(10):2348-2356. 
74. Maddison R, Prapavessis H, Clatworthy M. Modeling and rehabilitation following anterior cruciate ligament reconstruction. Ann Behav Med. 2006; 31(1):89-98. [PubMed: 16472043]

75. Abbott AD, Tyni-Lenne R, Hedlund R. Early rehabilitation targeting cognition, behavior, and motor function after lumbar fusion: a randomized controlled trial. Spine (Phila Pa 1976). 2010; 35(8):848-857. [PubMed: 20354468]

76. Morrey MA, Stuart MJ, Smith AM, et al. A longitudinal examination of athletes' emotional and cognitive responses to anterior cruciate ligament injury. Clin J Sport Med. 1999; 9(2):63-69. [PubMed: 10442619]

77. Noojin FK, Barrett GR, Hartzog CW, et al. Clinical comparison of intraarticular anterior cruciate ligament reconstruction using autogenous semitendinosus and gracilis tendons in men versus women. Am J Sports Med. 2000; 28(6):783-789. [PubMed: 11101098]

78. Ferrari JD, Bach BR Jr. Bush-Joseph CA, et al. Anterior cruciate ligament reconstruction in men and women: An outcome analysis comparing gender. Arthroscopy. 2001; 17(6):588-596.

[PubMed: 11447545] 


\section{Summary Box: What are the new findings?}

- Variables that may be associated with good functional outcome and patient satisfaction following anterior cruciate ligament reconstruction have been examined, but few studies have examined whether these variables are also associated with return to sport.

- There is weak evidence for some of the existing return to sport criteria following anterior cruciate ligament reconstruction.

- Weak evidence exists supporting an association between psychological variables and return to sport, suggesting that psychological variables should be considered for inclusion in return to sport criteria. 


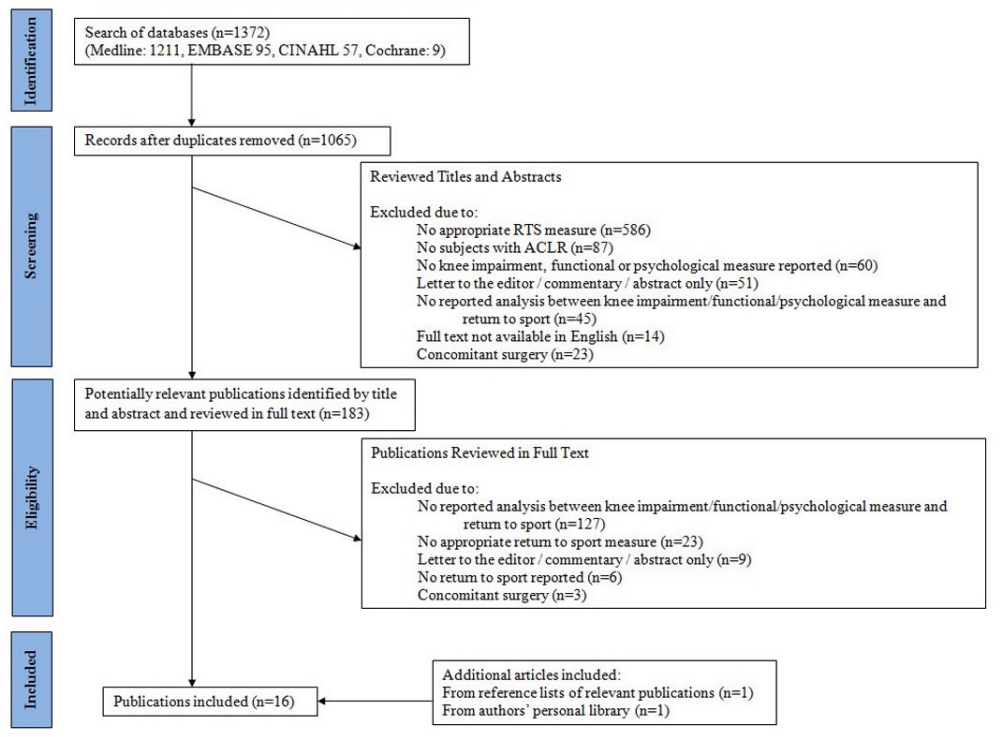

Figure 1.

PRISMA Flow Diagram of Search Results[53] 


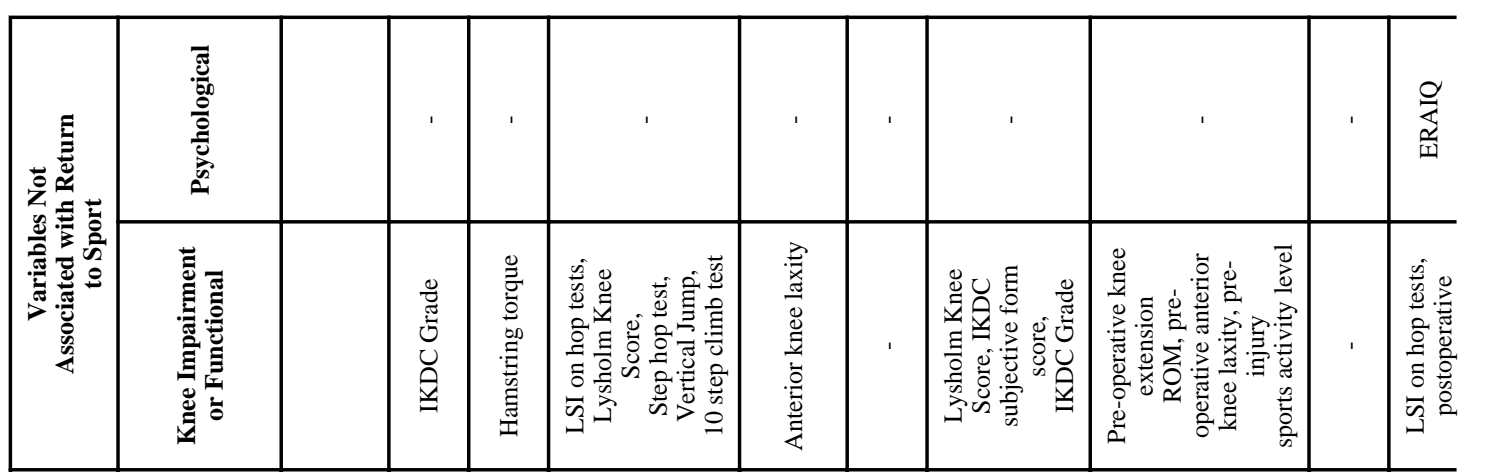

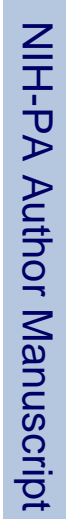

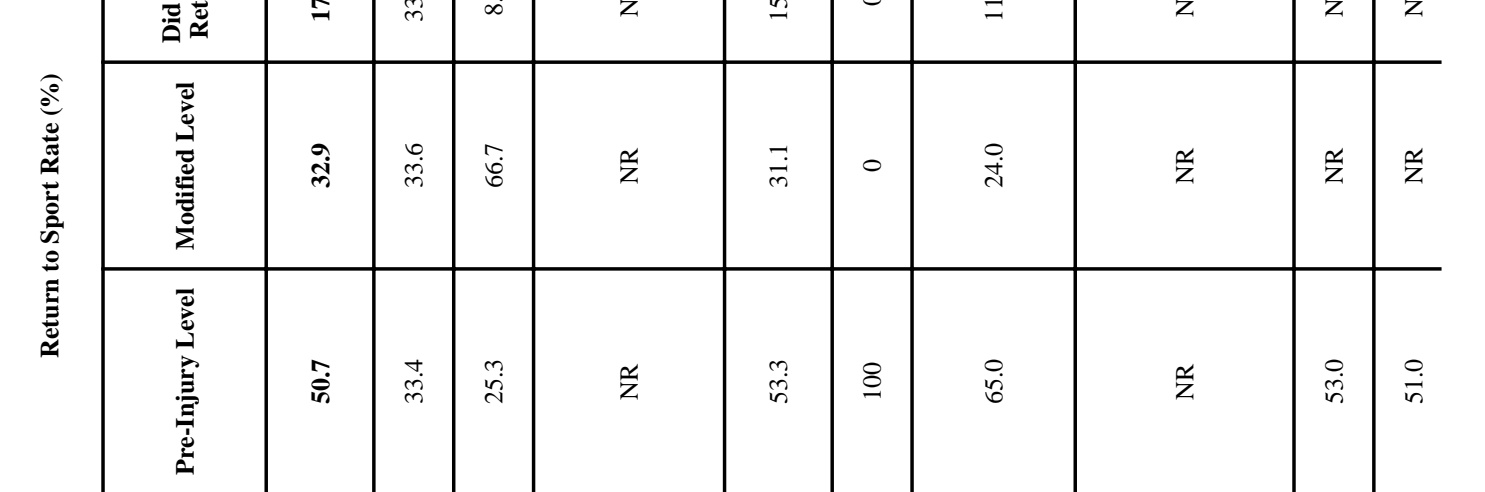

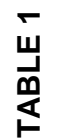

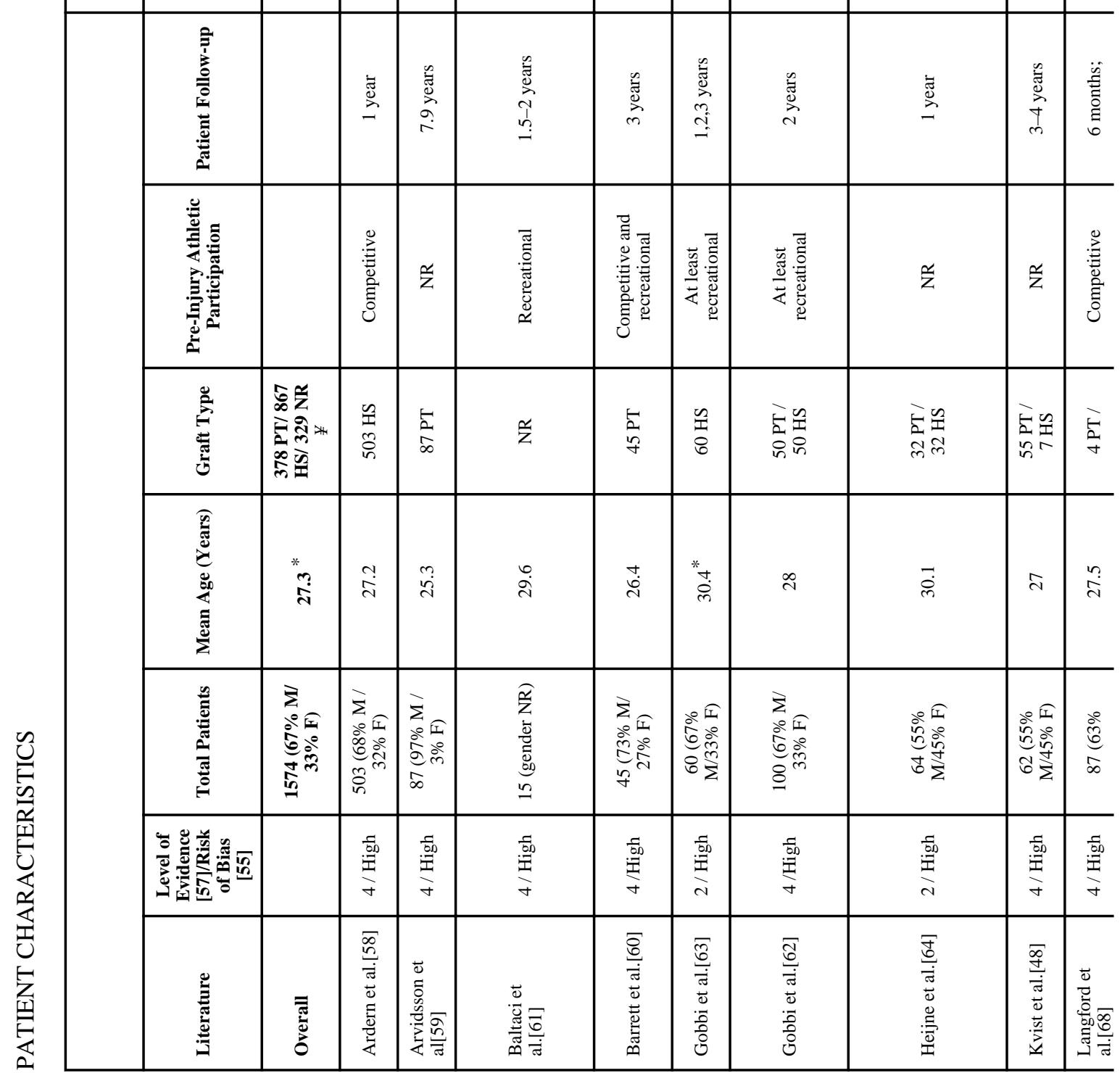




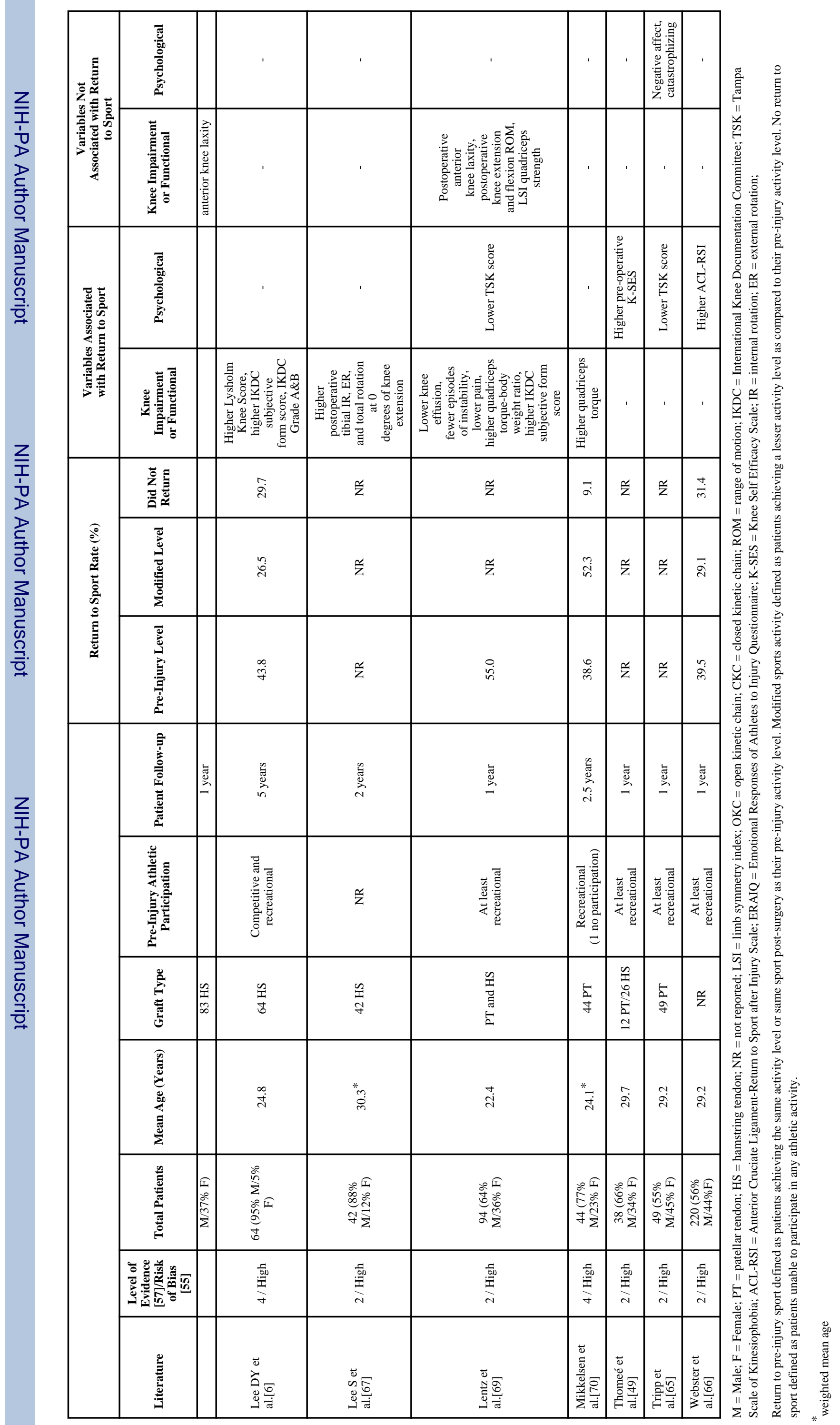




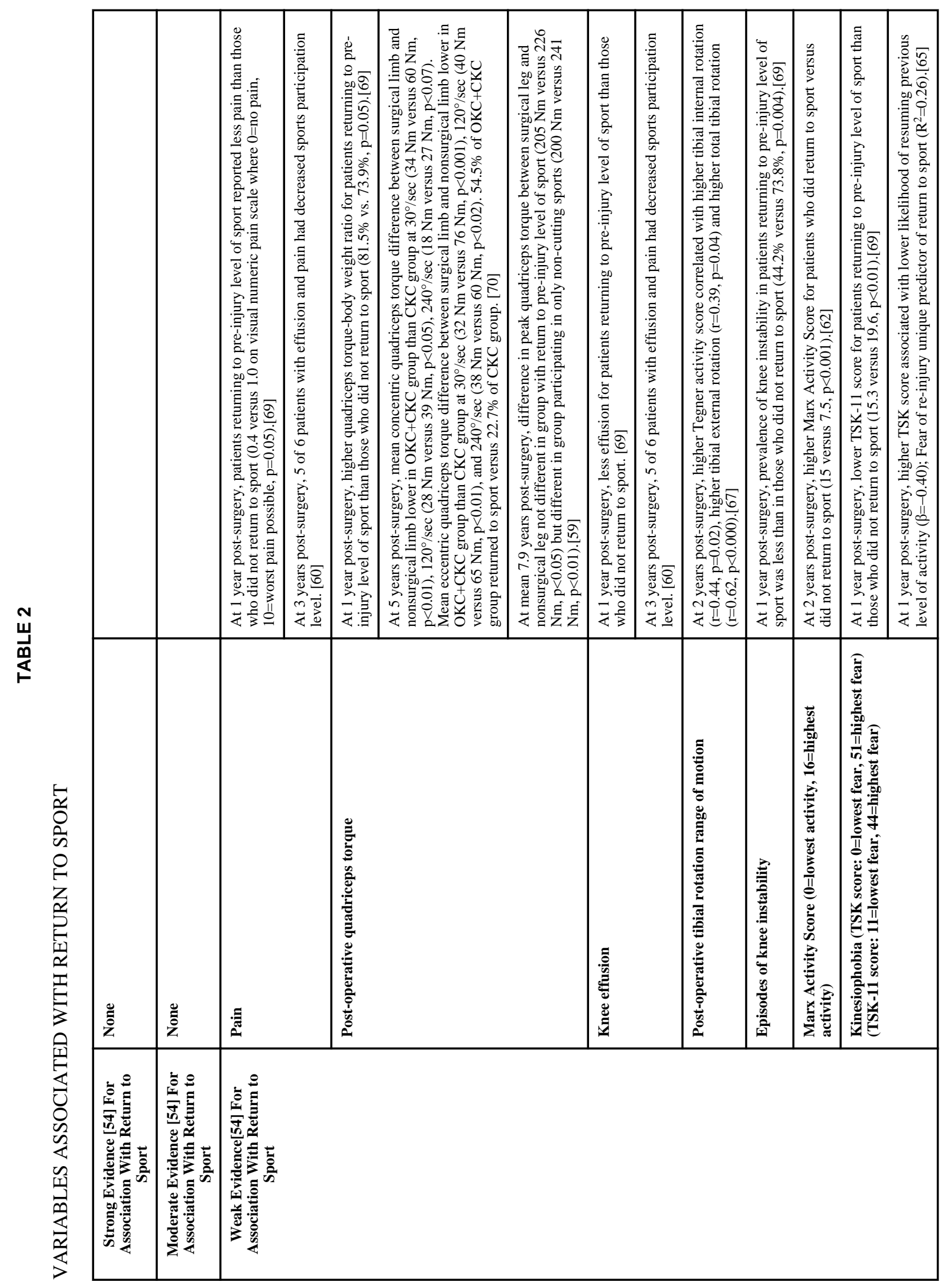

Br J Sports Med. Author manuscript; available in PMC 2015 March 01. 


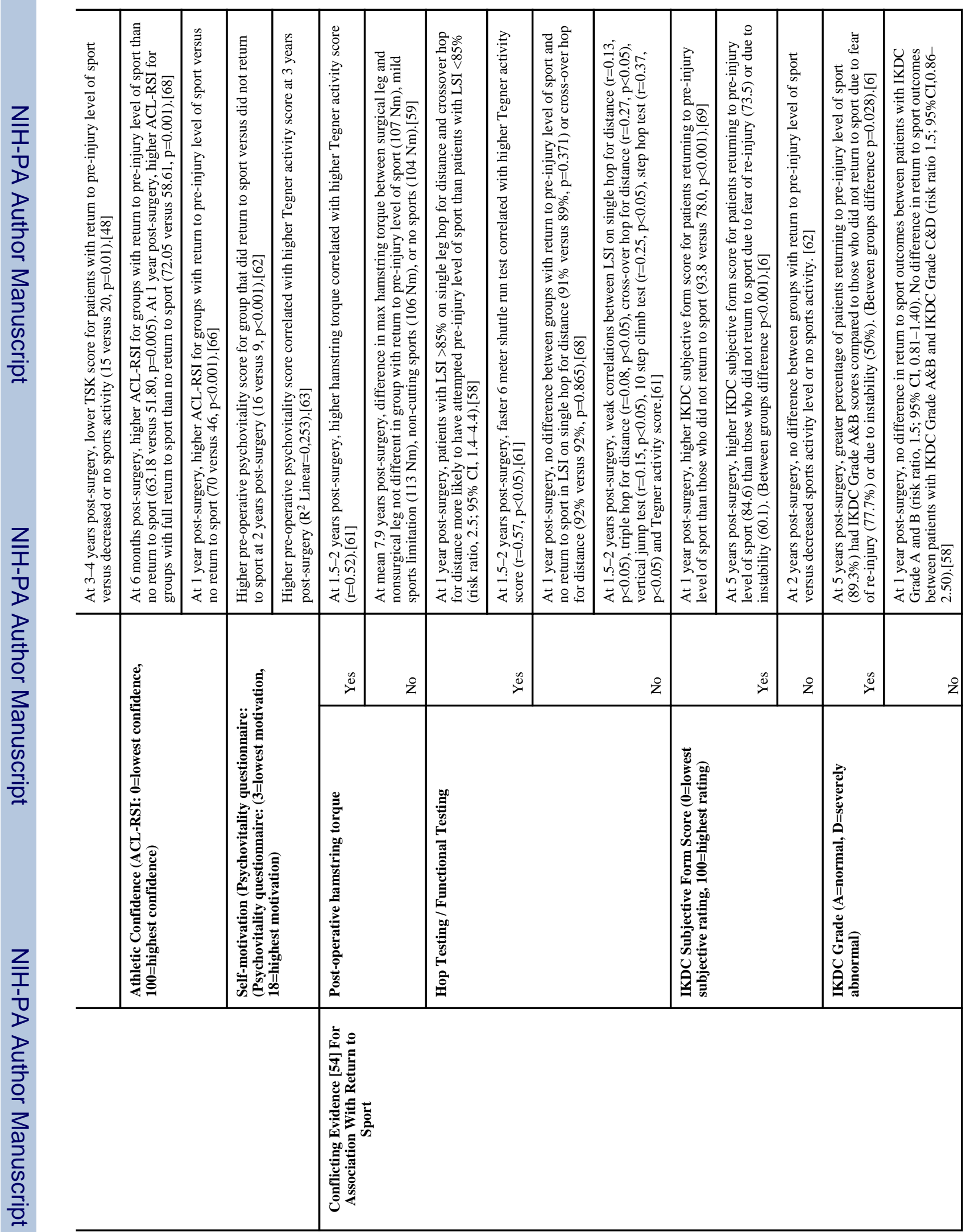




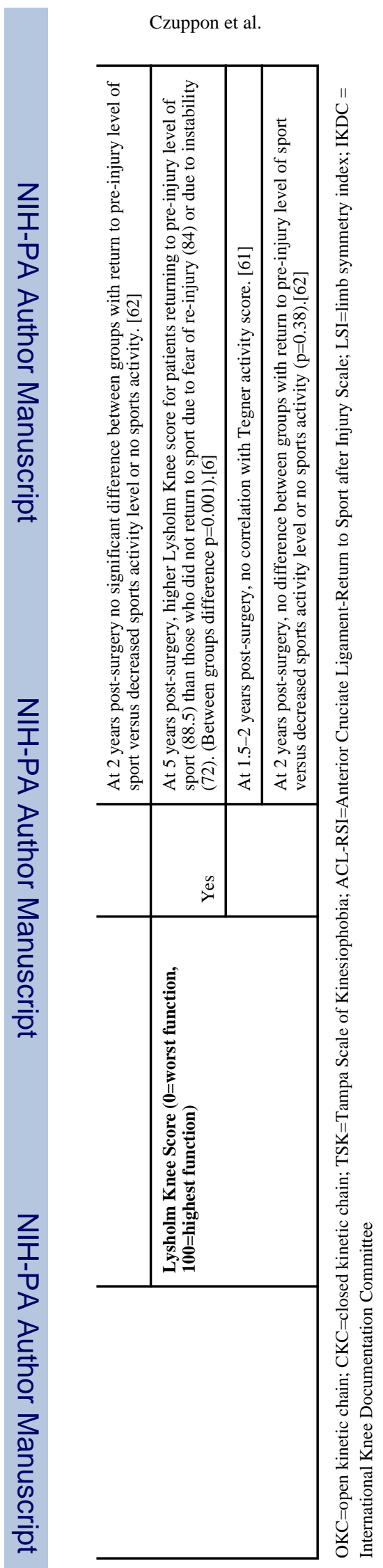

Page 27

Br J Sports Med. Author manuscript; available in PMC 2015 March 01. 